Federal Reserve Bank of Minneapolis

Research Department Staff Report 397

Revised April 2008

\title{
Changes in the Distribution of Family Hours Worked Since 1950*
}

\author{
Ellen R. McGrattan \\ Federal Reserve Bank of Minneapolis \\ and University of Minnesota
}

Richard Rogerson

Arizona State University

\begin{abstract}
This paper describes trends in average weekly hours of market work per person and per family in the United States between 1950 and 2005. We disaggregate married couple households by skill level to determine if there is a pattern in the hours of work by wives and husbands conditional on either husband's wages or husband's educational attainment. The wage measure of skill allows us to compare our findings to those of Juhn and Murphy (1997), who report on trends in family labor using a different data set. The educational measure of skill allows us to construct a longer time series. We find several interesting patterns. The married women with the largest increase in market hours are those with high-skilled husbands. When we compare households with different skill mixes, we also find dramatic differences in the time paths, with higher skill households having the largest increase in average hours over time.
\end{abstract}

* This paper was prepared for the volume Frontiers of Family Economics. The authors thank Tetyana Dubovyk for excellent research assistance. The data and codes are available at the Minneapolis Federal Reserve's website: www.minneapolisfed.org/research/sr/sr397.html. The views expressed herein are those of the authors and not necessarily those of the Federal Reserve Bank of Minneapolis or the Federal Reserve System. 


\section{Introduction}

One of the most dramatic changes in the U.S. economy over the last 50 years has been the substantial increase in hours of work by married women: although aggregate hours worked have been relatively constant, hours of work by married women have increased by roughly a factor of three. The desire to understand the economic forces behind this increase has spawned a large research literature. ${ }^{1}$

Central to assessing the impact of many economic forces is a theory of how the labor supply of various members of a household responds to changes in the relative opportunities faced by its members. The premise of this paper is that disaggregated household data have the potential to provide important additional information about these responses. In particular, given the importance of skill as a determinant of labor market opportunities and the large changes in the return to skill over time, we believe that data that disaggregate households by skill are likely to be informative about the forces that influence hours of market work within households. To this end, the objective of this paper is to present time series data on household labor supply that are disaggregated along the dimension of skill.

Juhn and Murphy (1997) present evidence on trends between 1960 and 1990 in family labor supply. They condition on skill proxied by the husband's wage and show that the rise in married women's labor input was concentrated among women married to high-wage husbands. Data availability forces them to impute wages over most of their sample. Since there is now an additional 15 years of data which do not require imputation and extrapolation, it is of interest to reexamine the patterns that they found. We also introduce a second measure 
of skill — educational attainment — which allows us to construct trends back to 1960 .

While some of our findings confirm those previously documented by Juhn and Murphy (1997), our study also uncovers several novel and interesting findings. In 1960, we find a relatively flat profile for married women's market hours and employment conditional on the educational attainment of the husband. On average, women married to high school dropouts, high school graduates, and men with some college worked about 11 hours per week. Women married to college-educated men worked on average about 9 hours per week. By 2005, this situation has changed dramatically. The average hours of wives of college-educated men increased almost threefold, whereas the average hours of wives of high school dropouts increased only 70 percent.

We also compare the time series changes in hours of work by both the household and its individual members across different skill mixes. In particular, we contrast couples in which each member has a college education with couples in which each member has only a high school education. Between 1960 and 1970, both household and individual hours follow a very similar path for both household types, but from 1970 on the changes are quite different. Household hours increase much more for the high-skill household, and this is accomplished by relative increases for both members. Of particular interest is that men in the high-skill household actually increase their hours of work after 1970, whereas men in the low-skill household decrease their hours of work.

While most of our analysis will emphasize time series changes in hours of market work, we also use data from the recent American Time Use Surveys (U.S. Department of 
Labor, Bureau of Labor Statistics 2003-2004) to examine how time allocations differ across households from different positions in the skill distribution. Our examination of the time use data of 2003-2004 yields a surprising observation. Although high-skill couples devote more time to market work than do low-skill couples, we find that time devoted to home production is roughly similar. It follows that low-skill couples enjoy more leisure than do high-skill couples. This finding contradicts the mechanism proposed by Ríos-Rull (1993) to reconcile cross-sectional and time series patterns in hours of work data.

An outline of the paper follows. In the next section, we describe the data set that we use for our analysis. Section 3 presents the aggregate facts from our data set, which serves to confirm patterns that are already well known. Section 4 presents the data disaggregated by household skill level, and Section 5 presents the time use data. Section 6 concludes.

\section{Data}

The findings in this paper are based on data from the decennial censuses from 1950 to 2000. The data for 2005 are from the American Community Survey (ACS). These data are available from the Minnesota Population Center's Integrated Public Use Microdata Series (IPUMS) (U.S. Department of Commerce, Bureau of the Census 1950-2005). For each survey year, we treat the universe of the sample as all 25 to 64 year olds, with one modification. We eliminate from our subsample any individuals that have variable EMPSTATD (employment status with detailed categories) equal to 12 or 15 . These individuals had jobs but were not at work when the survey was done. We also eliminate individuals who are married with a spouse present if their spouse had EMPSTATD equal to 12 or $15 .^{2}$ When we report statistics 
for the "total population," this is the universe that we use.

For each individual in our universe, we collect information on age, sex, marital status, educational attainment, employment status, hours of work, and income from wages and salaries. If the individual is married, we have the same information for the spouse. We also form certain subgroups. We refer to "families" as couples whose marital status is "married with spouse present" in which the husband is between the ages of 25 and 64 . We refer to "singles" (either men or women) as individuals whose marital status is "never married" and are between the ages of 25 and 64 .

In the appendix, we describe in detail the measures of average hours and hourly earnings that we use for this study. One issue that we face is comparability of data over time. Specifically, survey questions have changed between decennial censuses. The most important change is the survey question concerning weekly hours of work. Between 1950 and 1990, the respondent was to give hours worked last week. Between 1980 and the present surveys, the respondent was to give hours usually worked during the prior year. For the universe we use, the difference in weekly hours is about 2.3 percent or 0.7 hours per person, with last week's hours measure being higher than the usual hours measure. Because the change in the hours of work in the overlap period from 1980 to 1990 is very close, we use estimates of hours for 1950-1990 based on last week, and we use estimates of the differences in hours between 1990 and 2000 and between 2000 and 2005 based on the usual hours measure. (See the appendix for more details.)

To construct wage rates, we need data on wages and salaries corresponding to partic- 
Figure 1. Aggregate Hours Per Person, Ages 25-64

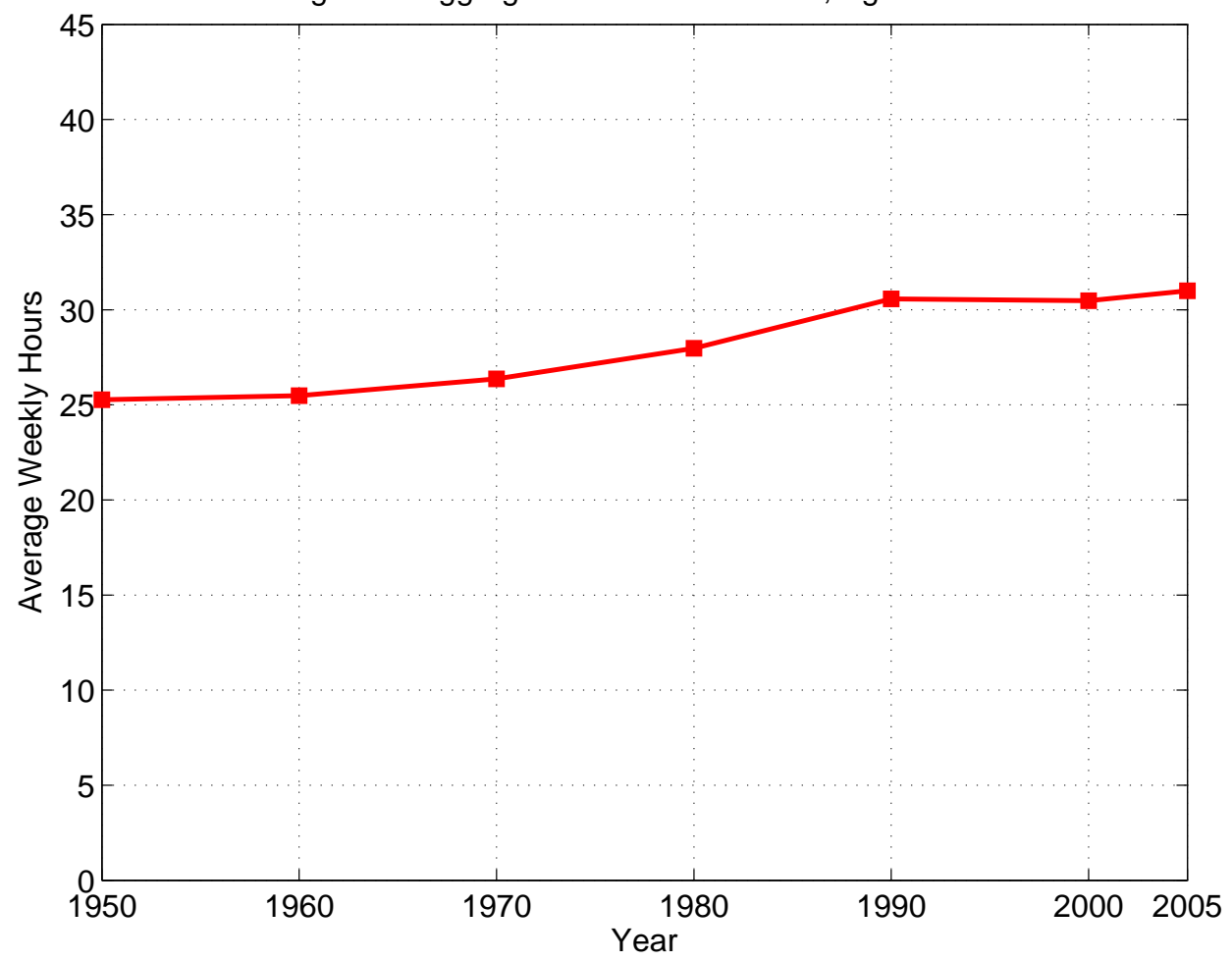

ular hours. The advantage of the usual hours measure is that it reflects usual weekly hours last year, which is the period for which wage income data are available.

\section{Aggregate Patterns: 1950-2005}

When examining changes in hours worked at the aggregate level, standard practice is for the unit of observation to be the individual. So, for example, the standard measure of hours worked at the aggregate level is aggregate hours per adult, or per adult of working age. Figure 1 plots aggregate hours of work per person for individuals ages 25-64 for the United States over the period 1950-2005. This series shows a positive trend, having increased from around 25 hours per week in 1950 to around 30 hours per week in $2005 .^{3}$

In McGrattan and Rogerson (1998, 2004) we examined the behavior of hours per 
Figure 2A. Average Weekly Hours Per Person of Families and Singles

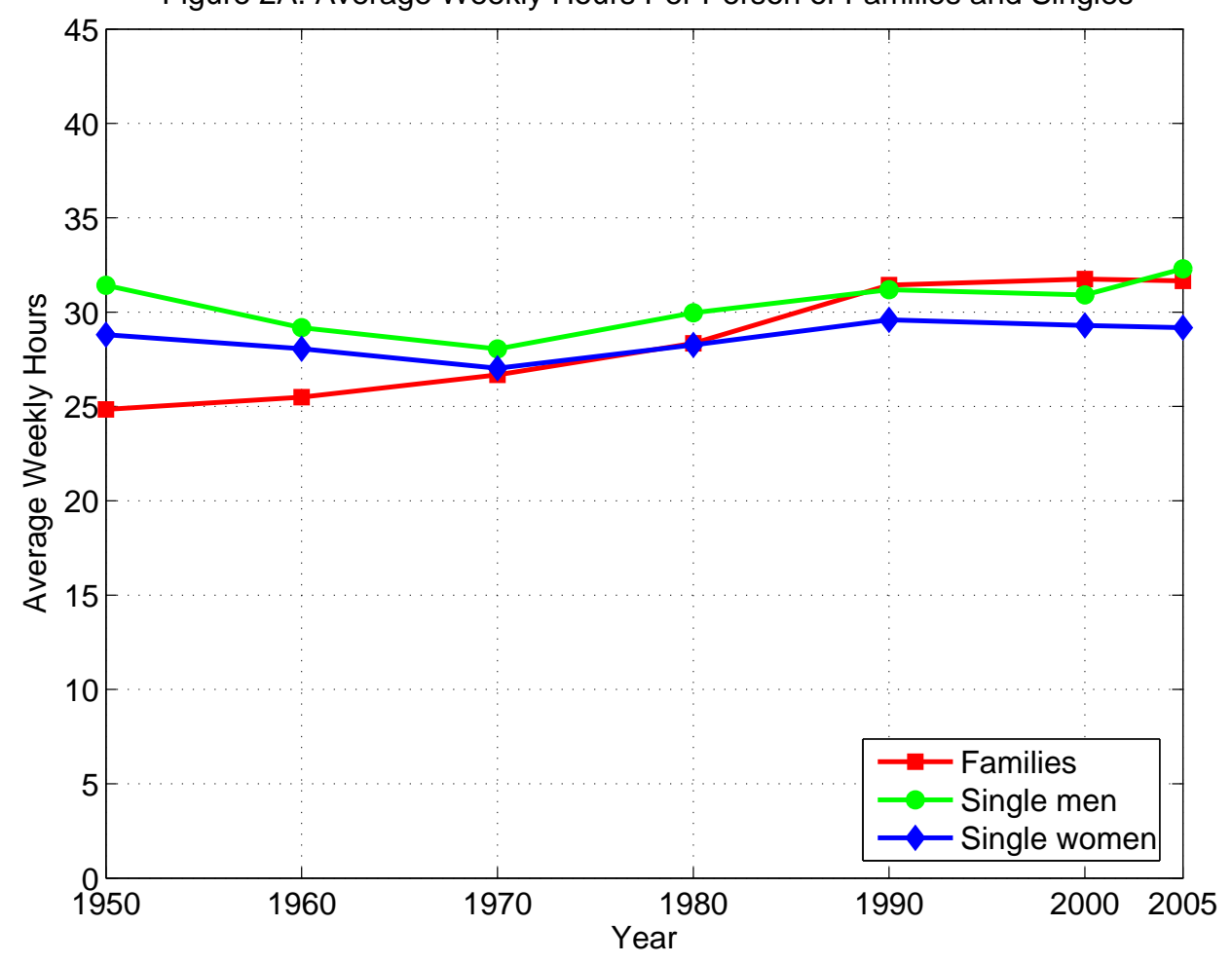

person at a disaggregated level by considering various individual characteristics. A key finding of those studies was that the relative constancy at the aggregate level was the result of very large changes across groups that tended to offset each other. In this paper, our goal is to examine hours of work at the household level rather than the individual level.

We begin by presenting hours of work over the period 1950-2005 by three different types of households: single females, single males, and married couples. Figure 2A presents the time series. Several findings emerge from this figure. First, hours of work by single males and single females exhibit virtually no trend. Second, single females work about 95 percent as much as single males, and in view of the first observation, this ratio has remained relatively constant. Third, hours worked by married couples exhibit a significant positive trend over the period, increasing by roughly 25 percent. Interestingly, this entire increase occurs between 


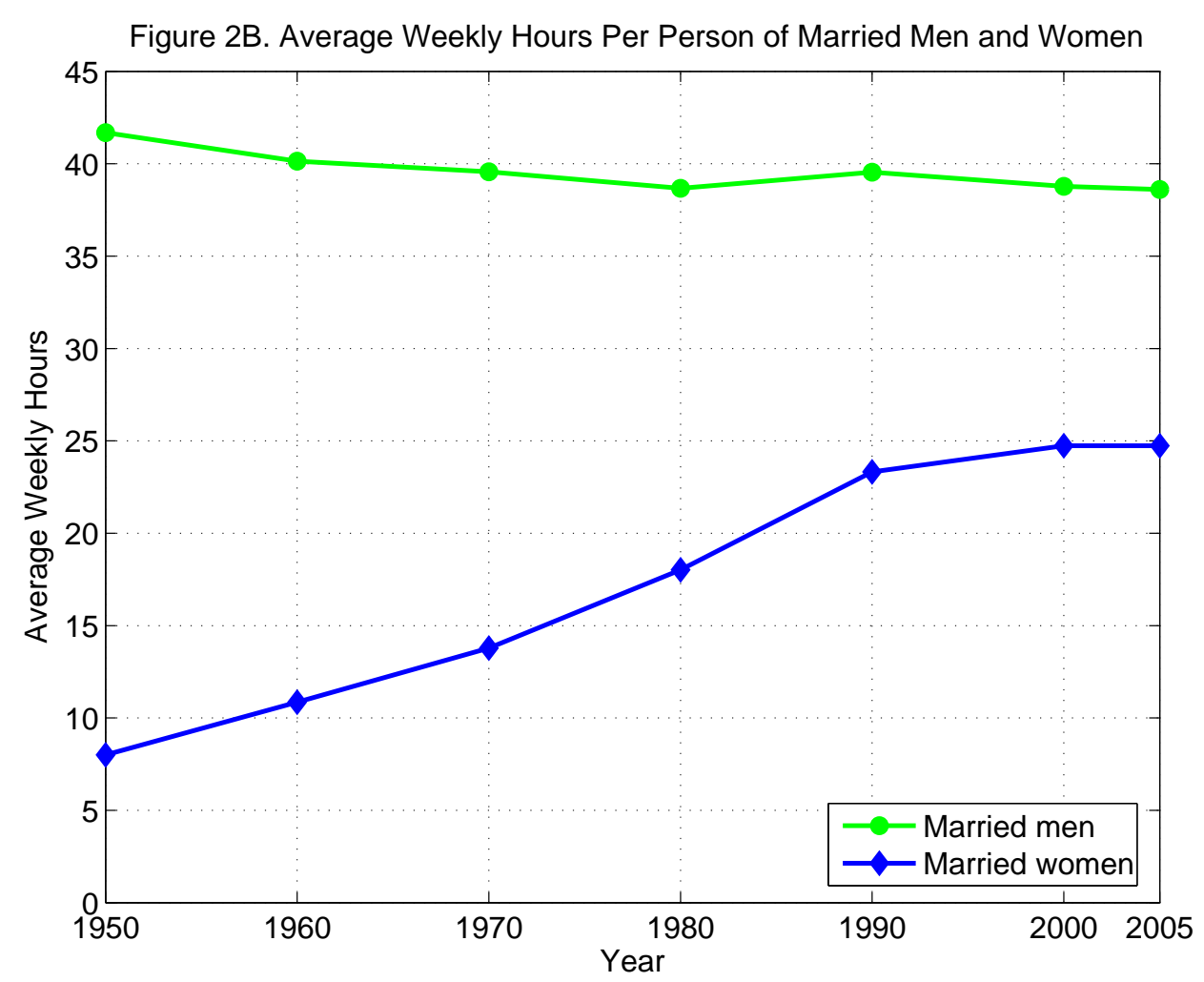

the years 1950 and 1990. The rate of increase is itself increasing over the period 1950-1990, experiencing its largest increase from 1980 to 1990. By the end of the period, hours in married couples are basically the same as average hours among single households.

What is the source of the increasing hours among married couple households? Figure 2B displays the series for hours worked by married men and women. It shows that the net increase of 12 hours per household (or 6 hours per person) is the result of a decrease of about 4 hours by married men and an increase of about 16 hours by married women.

While the previous figures have looked at the evolution of average hours of work, we now take a look at what has happened to the distribution of hours worked. Figures $3 \mathrm{~A}$ and 3B plot the coefficient of variation for hours worked by household type and then by members within married couple households. 


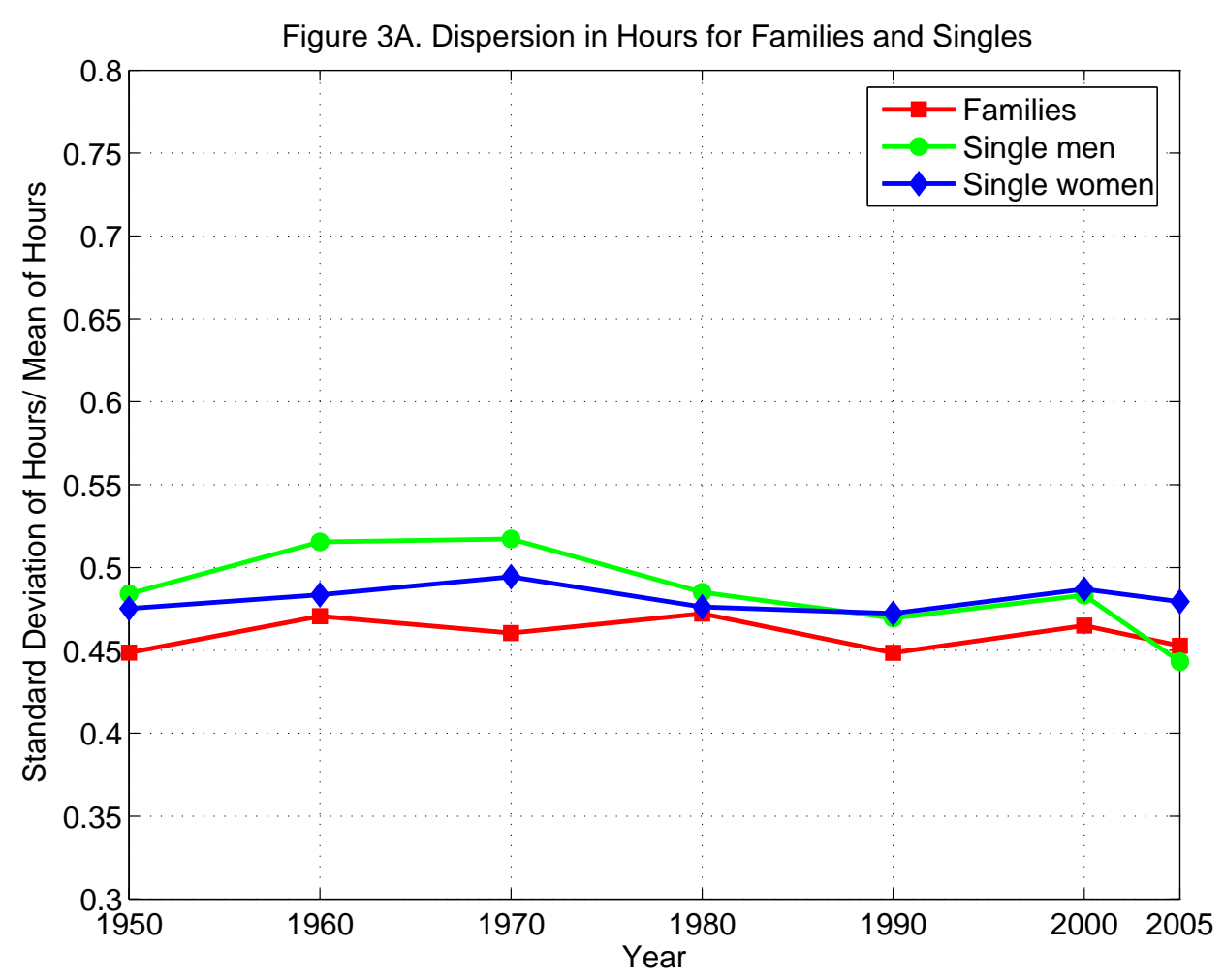

Figure 3A shows what has happened to the dispersion of hours worked for each of three household types: single males, single females, and married couples. Dispersion is relatively constant over time for each household type and is relatively constant across household types as well. Figure 3B shows what has happened within married couple households.

This figure shows a dramatic decrease in the dispersion of hours worked among married women. This is generated by the large increase in employment rates for married women over this period. In contrast, married men exhibit an increase in dispersion over this time period. Although this change is small in comparison to that experienced by married women, the increase is still substantial, amounting to roughly 25 percent. It is somewhat remarkable that the dramatic decrease in dispersion among married women has not led to any change in the dispersion of hours worked across married couple households. One factor is that the 
Figure 3B. Dispersion in Hours for Married Men and Women

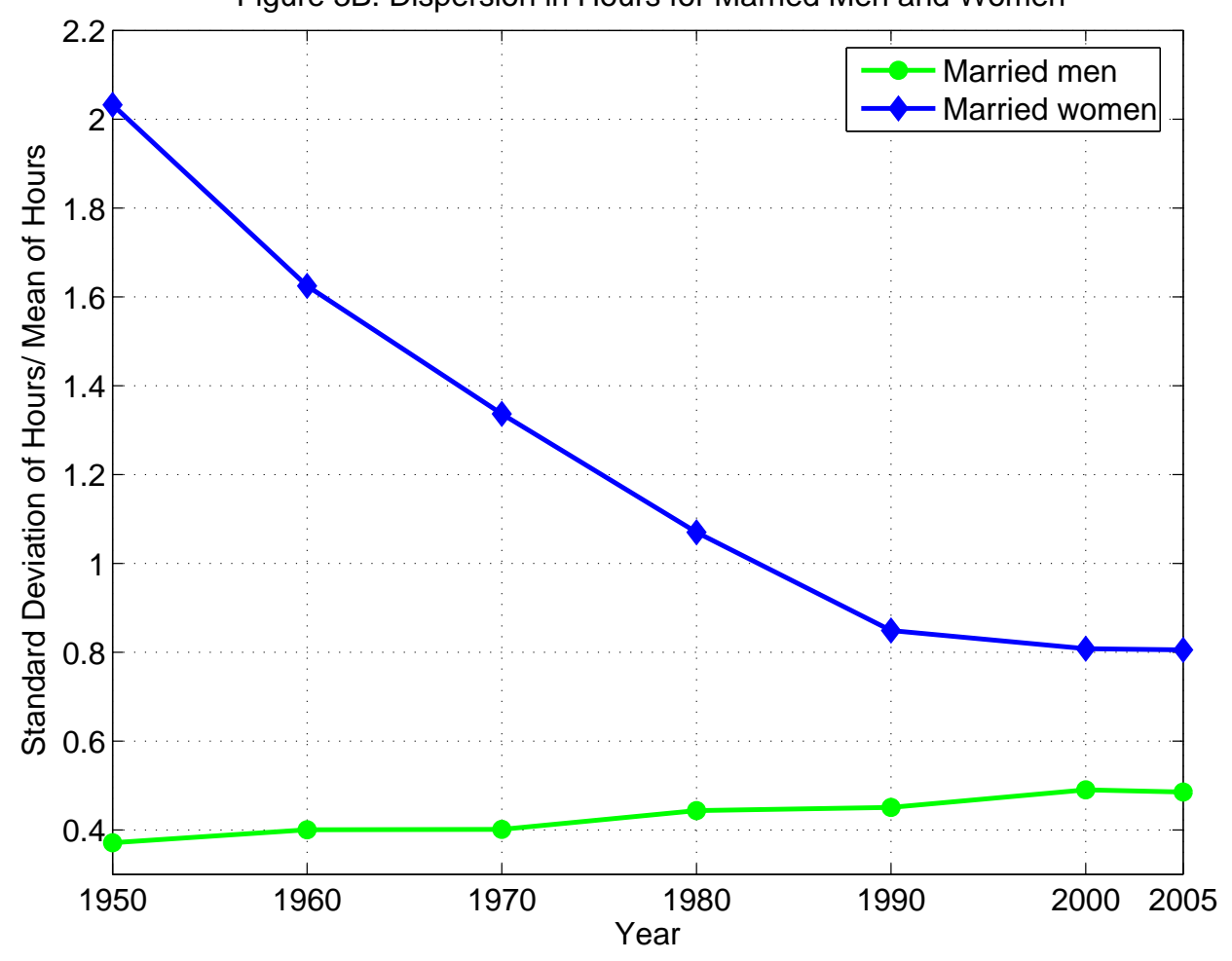

relative importance of married women in terms of hours of work at the household level has increased over time. Hence, while hours of work are very dispersed across married women in 1950, married women account for only a small part of total household hours, thereby diminishing their impact on dispersion in household hours.

Another fact that influences the dispersion of hours of work across households is the correlation of hours of work among household members. In view of this, it is also of interest to ask what has happened to this correlation. Figure 4 plots the time series for this correlation.

Two features of this plot are worth noting. First, between 1970 and 2000 this correlation displays a marked increase. Second, despite this increase, however, the correlation at its maximum is still less than 15 percent, and so to a first approximation, it is not far wrong to say that the correlation of hours worked across household members is roughly zero. 


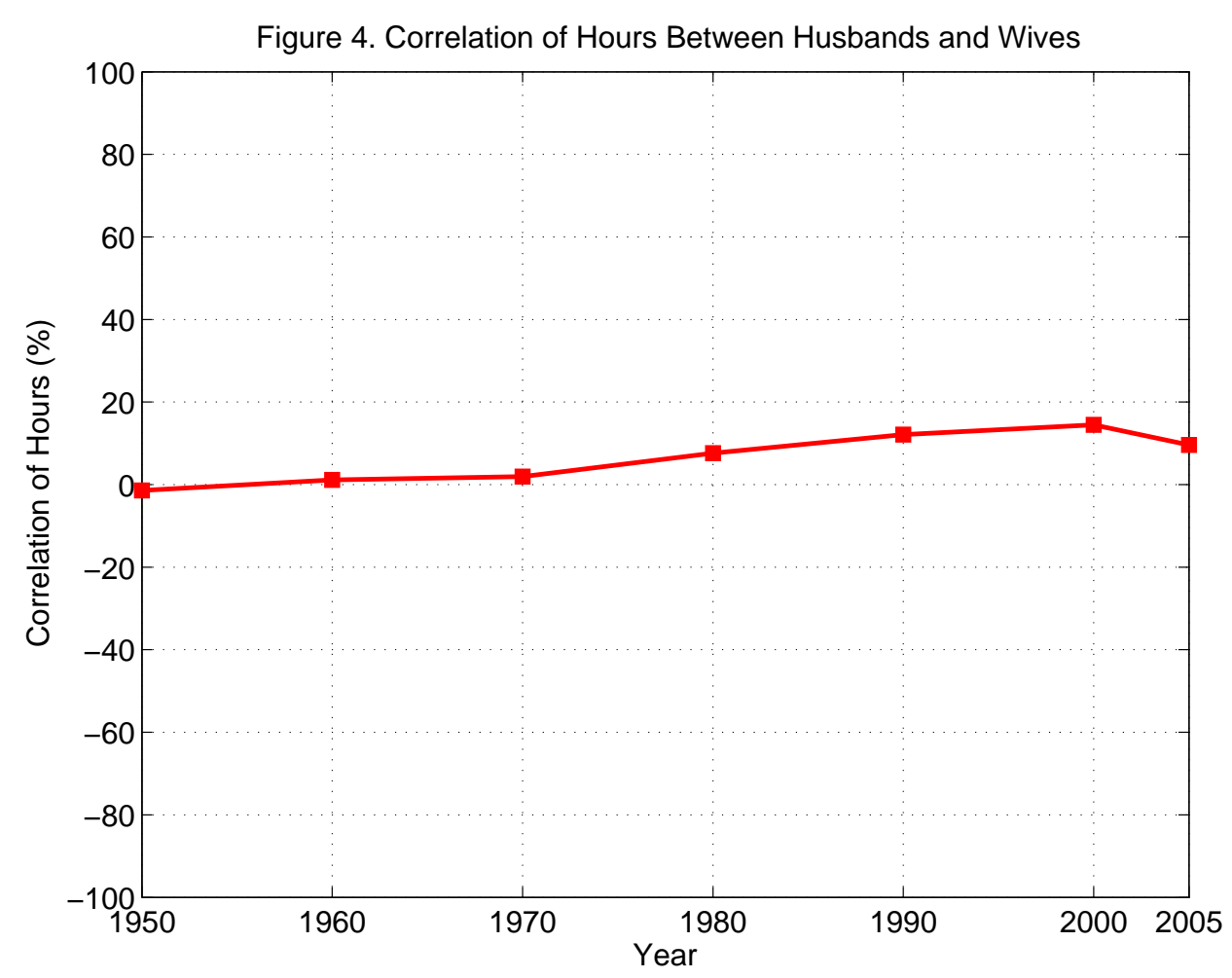

\section{Disaggregated Patterns: Household Hours by Skill Level}

In this section we undertake a disaggregated analysis of household hours of work. In particular, we consider hours of work at the household level and its components as we vary the skill level of the household. We are interested in this disaggregation for several reasons. First, to the extent that economists are interested in understanding the forces that have shaped the change in hours worked at the household level, and in particular the increase in hours of women, understanding how households respond to changes in their economic environment is very relevant. Examining how hours worked at both the household and individual-member level vary with the skill level of members has the potential to shed considerable light on the economic forces that shape household hours. Second, the earlier work of Juhn and Murphy (1997) has presented some evidence on these patterns using data from the 1960s through the 1980s. Data availability forced them to obtain much of their data via extrapolation for the 
1960s and 1970s. Since there is now an additional 15 years of data which does not require extrapolation, it is of interest to reexamine the patterns that they found.

We will examine skill in three different settings. The first method parallels the analysis of Juhn and Murphy, except that we consider the period 1980-2005. In particular, we classify couples according to the wage decile to which the husband belongs. We then examine how hours of wives, husbands, and families have varied across these groups, both in the cross section and over time.

The second analysis that we undertake is similar in spirit, but instead of grouping households into skill categories based on the husband's wage decile, we instead group households into skill groups based on the husband's educational attainment. While education may be a cruder measure of skill than wages, we are able to perform this analysis for the period from 1960 to 2005.

The two analyses just described both classify households into skill categories based on the husband's skill level. This grouping obviously abstracts from heterogeneity in the wife's skill level. In principle we should be able to get additional information by examining how the pair of skill levels for a married couple influences hours worked. In our third analysis, we look at hours worked based on the pair of educational attainments for a couple.

\section{A. Skill Based on Husband's Wage}

We proceed in turn with each of the analyses just described. Figures $5 \mathrm{~A}-5 \mathrm{C}$ plot hours worked by households, women, and men in 1980 and 2005 by wage decile of the husband. 
Figure 5A. Wife's Hours Conditional on Husband's Wage

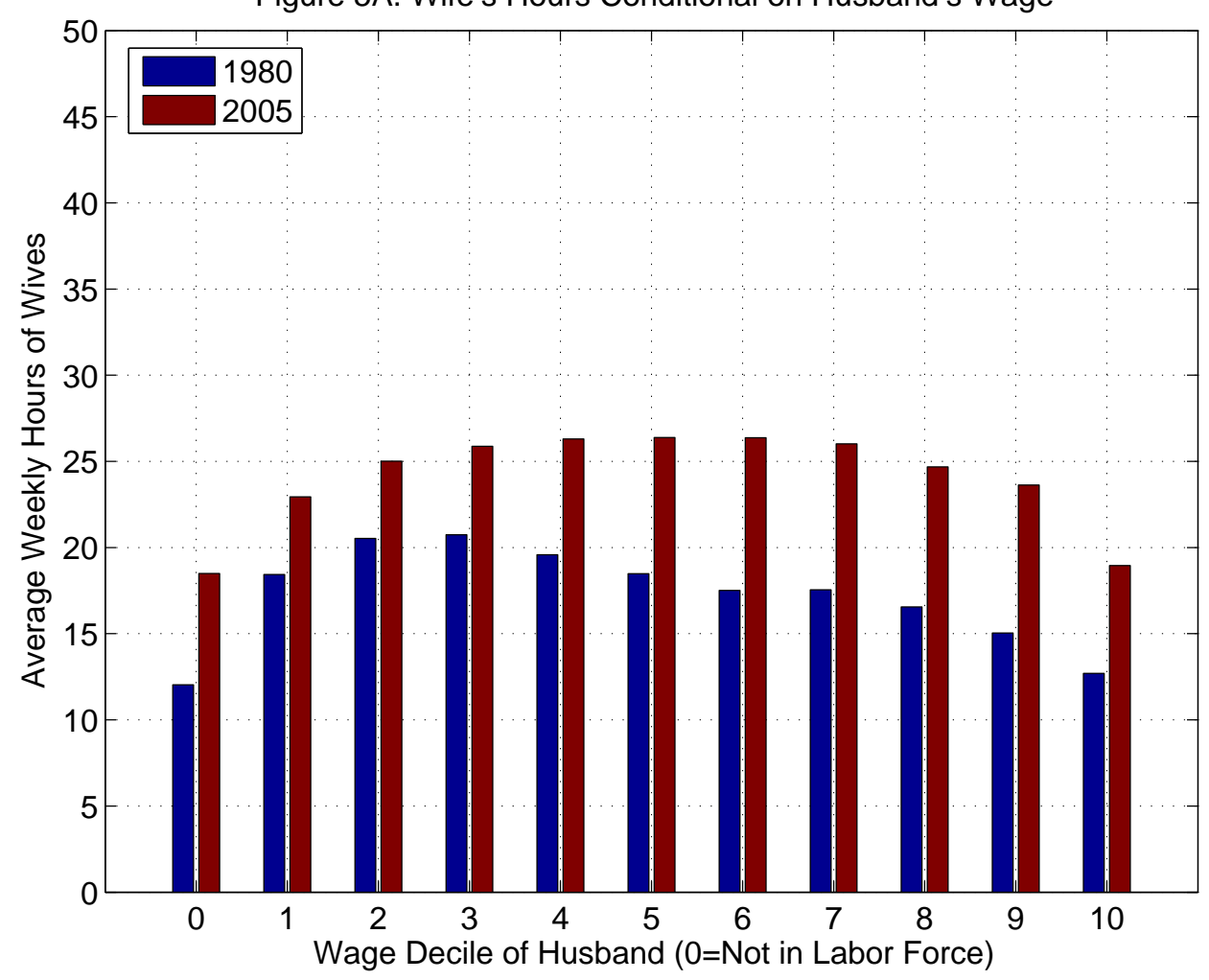

Each graph contains two bars for each decile: the first bar represents hours worked in 1980, while the second represents hours worked in 2005. We begin with Figure 5A, which plots married women's hours. Several patterns are worth noting. First, hours have increased for women in all groups. Second, the increase was most pronounced for women in the higher wage groups. As a result of this second observation, the cross-sectional profile has changed considerably. In 1980 the hours distribution peaked in the third decile and decreased rather smoothly throughout the remainder of the distribution. In contrast, in 2005 the level of hours worked is relatively constant from the third through the seventh deciles, with slightly lower values at the edges of the distribution.

We noted earlier that hours worked by married women rose only modestly since 1990. (See Figure 2B.) It is interesting to note that all of the increase between 1990 and 2005 was 
due to women whose husbands are in wage deciles four through nine.

Juhn and Murphy (1997) compare annual hours of wives by husband's wage decile using the March Current Population Survey from 1968 to 1992 and the 1960 decennial census. They find that the largest increase in hours over this period occurs for women with husbands in the high-wage deciles - dispelling the conventional wisdom that the rise in married women's labor market participation was concentrated among women married to low-wage husbands. Between 1970 and 1990, Juhn and Murphy estimate that the average market hours for women with husbands in the top four wage deciles increased 12 hours per week. Women with husbands in the highest decile increased their labor input from roughly 8 hours per week to 20 hours per week - a 250 percent increase.

Our findings are consistent with Juhn and Murphy's and show that the largest changes occurred for women with high-wage husbands. The largest hour differences between 1980 and 2005 are in wage deciles six through nine, which show an increase in average weekly hours of roughly 8 to 9 hours per week. In percentage terms, the increases are 50 to 60 percent over the 25-year period. Women with husbands in the highest decile increased their labor input from 12.7 hours per week to close to 19 hours, with almost all of the change coming between 1980 and 1990 (not shown). In 1990, we estimate that the wives of husbands in the top wage decile worked 18.7 hours per week. Thus, the last 15 years has seen little change for this group. Similarly, for the other families, most of the change in the wife's hours occurred during the 1980 s.

Next we look at Figure 5B, which shows the changes in hours worked by husbands 

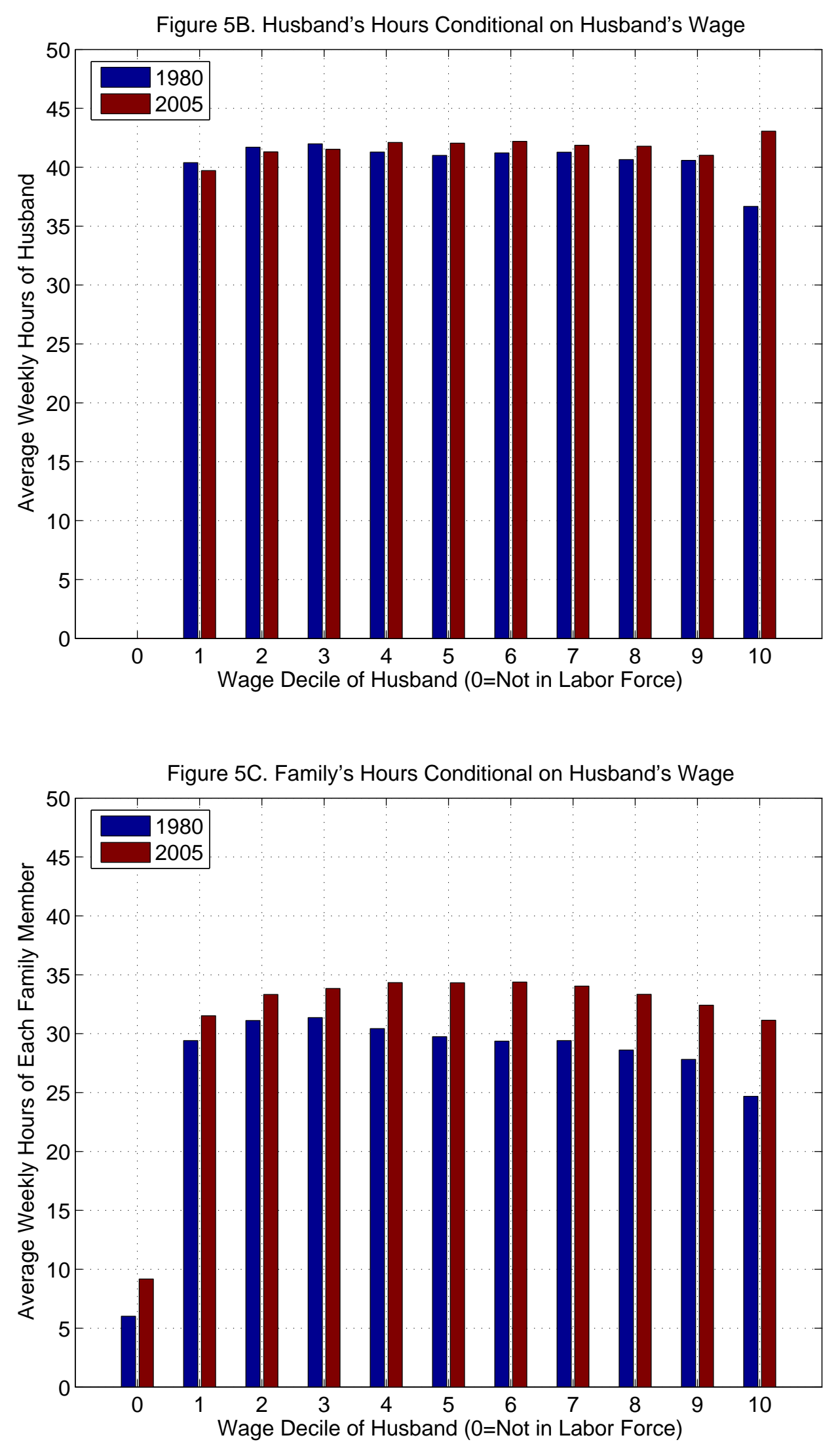
by deciles of the husband's wage distribution. In 1980, hours worked are virtually flat for the first nine deciles, and then decrease significantly for the last top decile. Interestingly, between 1980 and 2005 there is a sharp difference between the changes at the top and the bottom of the distribution. In particular, hours worked fall for the lowest three deciles, but increase for the top three deciles. While in 1980 the highest decile has the lowest hours of work, in 2005 it has the highest hours of work. These changes are also evident in the period 1990-2005 (not shown).

Figure 5C shows the changes in family hours of work by deciles of the husband's wage distribution. This figure shows a pattern similar to that observed for married women. Specifically, hours increase for all deciles, but the increases are largest for the highest deciles. While the distribution is roughly single peaked with its maximum in the third decile in 1980, the distribution is close to being flat in 2005 .

\section{B. Skill Based on Husband's Educational Attainment}

Next we turn to the similar analysis, except that we use educational attainment as our measure of skill. This analysis is carried out for the period 1960-2005, but to facilitate comparison with the previous analysis based on wages, each graph provides information about hours worked at three different points in time: 1960, 1980, and 2005. Figures 6A-6C show the results.

We begin with Figure 6A, which shows the results for women. The results are quite striking. In 1960, hours worked by women are virtually the same - 11 hours per week - for the first three educational groups of husbands and roughly 9 hours per week for wives of 


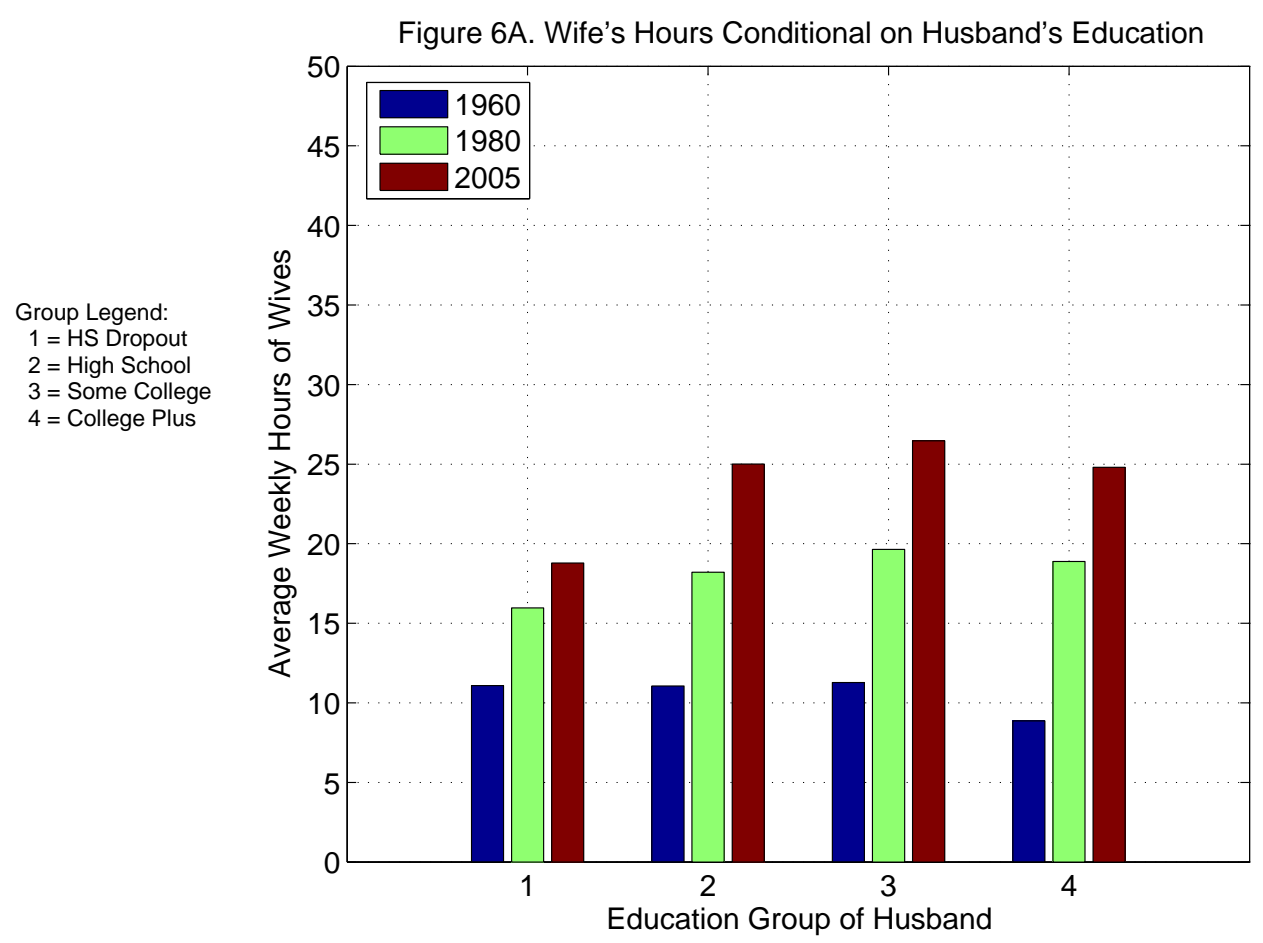

college-educated men. Between 1960 and 1980 there is a dramatic increase in hours worked by all groups, but there is a clear difference in the change in average weekly hours for wives of high school dropouts, which is nearly 5 hours per week, and that for wives of the college educated, which is 10 hours per week. By 2005, the hours profile is an inverted U shape, with wives of men with some college working the most on average: 26.5 hours per week.

Next, we consider the change in the average weekly hours of husbands for the four educational groups. This is shown in Figure 6B. Unlike their wives, the husbands in each educational group have decreased their average hours between 1960 and 1980. The largest decline is for the high school dropouts who worked 38.5 weekly hours on average in 1960 and 31.7 hours in 2005 . This is a large decline relative to the college-educated husbands whose hours fell by only 1 hour per week on average.

Figure $6 \mathrm{C}$ shows the family weekly hours conditional on the husband's educational 

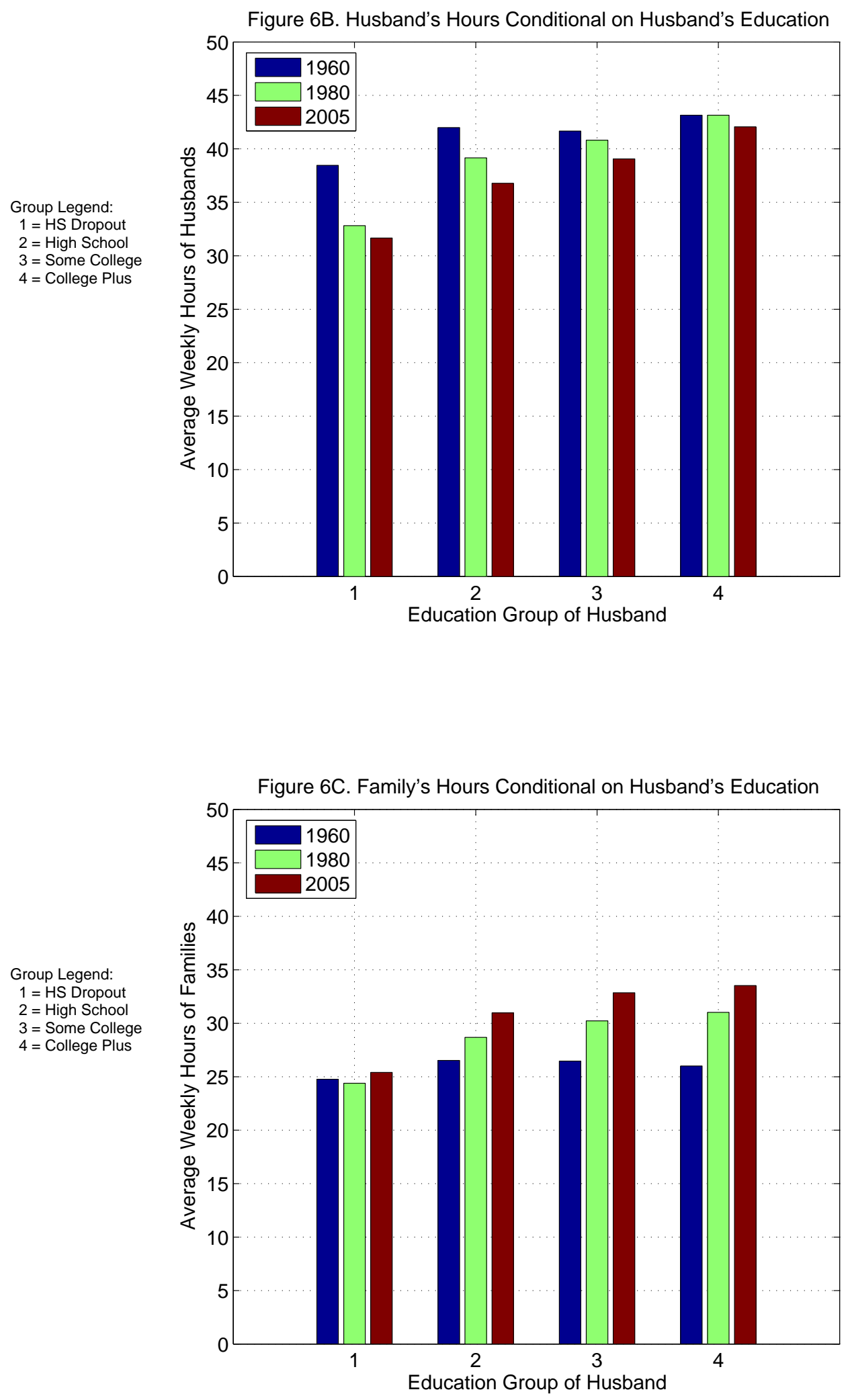
attainment. For couples in which the husband is a high school dropout, the average weekly hours have remained roughly constant at 25 hours per week. For couples with a collegeeducated husband, on the other hand, average weekly hours went from 26 hours per week in 1960 steadily up to 33.5 hours per week in 2005. This large increase was due to the significant rise in the wives' hours.

It is interesting to compare the 1980 and 2005 hours profiles for the two measures of husband's skill. Figures 5A and 6A both show average weekly hours of wives conditional on husband's skill. If we condition on husband's wage, we see that the peak of the profile shifted between 1980 and 2005, with wives of low wage earners (second and third deciles) working the most in 1980 and the wives of middle wage earners (fourth through sixth deciles) working the most in 2005. If we condition on husband's educational attainment, we find that the peak in the hours profile in both 1980 and 2005 is the average weekly hours of wives of men with some college.

Figures $5 \mathrm{~B}$ and $6 \mathrm{~B}$ both show average weekly hours of husbands conditional on husband's skill. Figure 5B is constructed for husbands in the labor force, while Figure $6 \mathrm{~B}$ is constructed for all husbands, including those not in the labor force. Because the groups of husbands are different in the two plots, we see different patterns between 1980 and 2005. The main difference is the hours of the higher skilled husbands, which rise if we condition on wage and fall if we condition on educational attainment.

When we compare the family hours for the two measures of skill, we see a different pattern again. Figure 5C shows a shift in the profile of family hours similar to the shift for 
wives. Figure 6C shows that the profile was increasing in husband's skill level in both 1980 and 2005. This figure shows that families with college-educated husbands work the most weekly hours on average, which has been the case since 1980 .

\section{Skill Based on Couple's Educational Attainment}

Lastly, we turn to the analysis based on classifying couples on the basis of the pair of skill levels, rather than just the skill level of the husband. Even with the somewhat coarse grouping based on four categories of educational attainment, we still end up with 16 different types of households. In the interest of space, rather than presenting results for the entire set of groups, we instead choose to focus on two groups that we think typify the variation in skill across households. Specifically, we will contrast one group of households in which both members have high school as their educational attainment with another group in which both members have college degrees. Figure $7 \mathrm{~A}$ plots the hours worked by male and female for each group.

The results are quite striking. In 1960 and 1970, there is very little difference in the hours worked across households: in each case men work substantially more than women, but the levels are basically independent of educational attainment. But by 2005 there are large differences across these households: the college-educated household works roughly 15 percent

more than the high school-educated household. Both men and women in the college-educated household work more than their counterparts in the high school-educated household. In contrast to declining hours of work for married men in the aggregate, we see that since 1970, married men in college-educated households have actually increased their hours of work at 


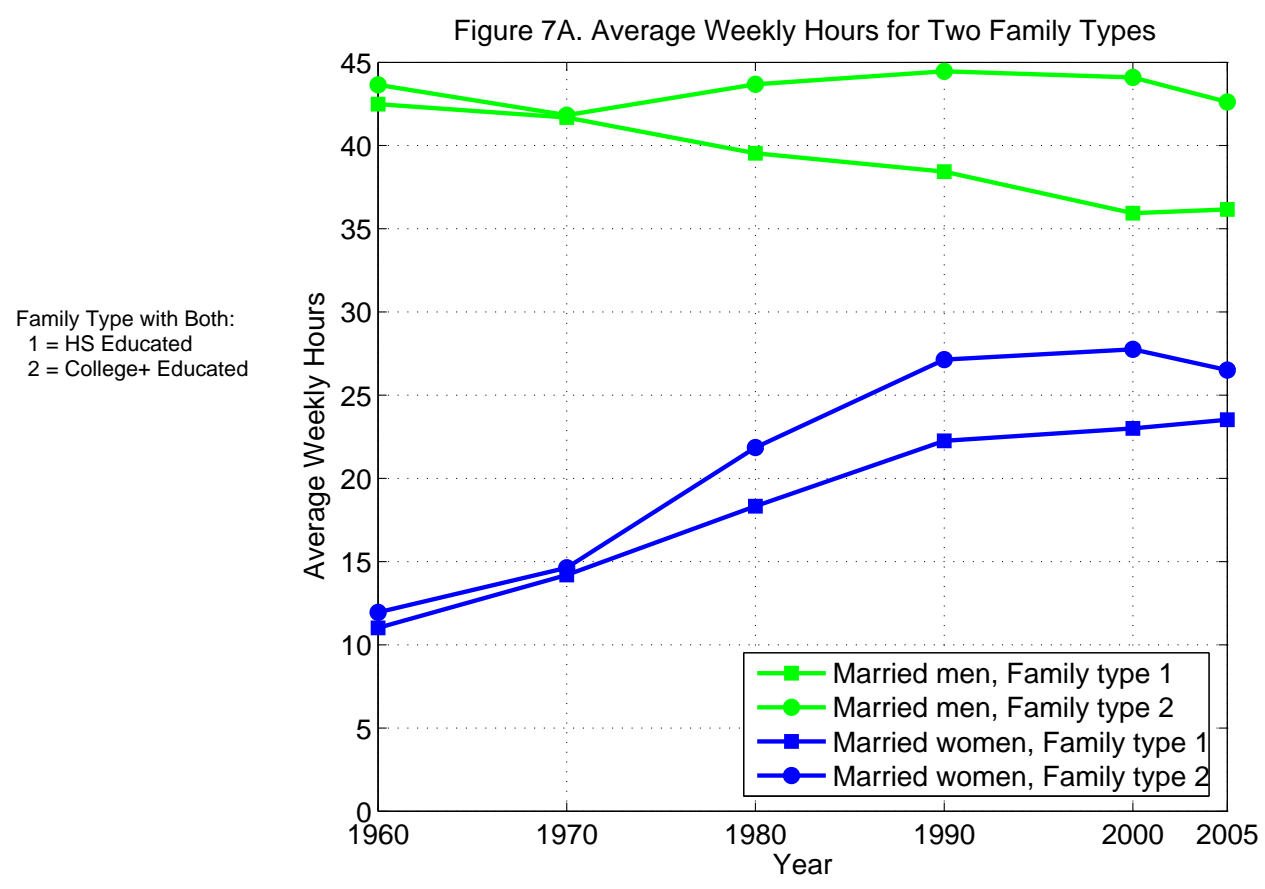

the same time that their wives have increased their hours of work.

Figure 7B shows the analogous picture, but for employment rates rather than hours. Note again that large differences have emerged since 1970. The differences in employment rates in 2005 account for roughly three-quarters of the differences in hours across households. Note also for men in college-educated households that their employment rate actually decreased from 1970 to 2005. Given that hours per person increased somewhat for this group, it follows that hours per worker has increased significantly for this group.

Lastly, we think it is interesting to examine hours worked for a woman of a given skill level conditional on the skill of her husband. With this in mind, Figures $8 \mathrm{~A}-8 \mathrm{D}$ show the changes in this cross-sectional relationship over time for women from four different educational groups.

A few interesting patterns appear in these figures. First, consistent with earlier find- 
Family Type with Both: $1=$ HS Educated $2=$ College + Educated

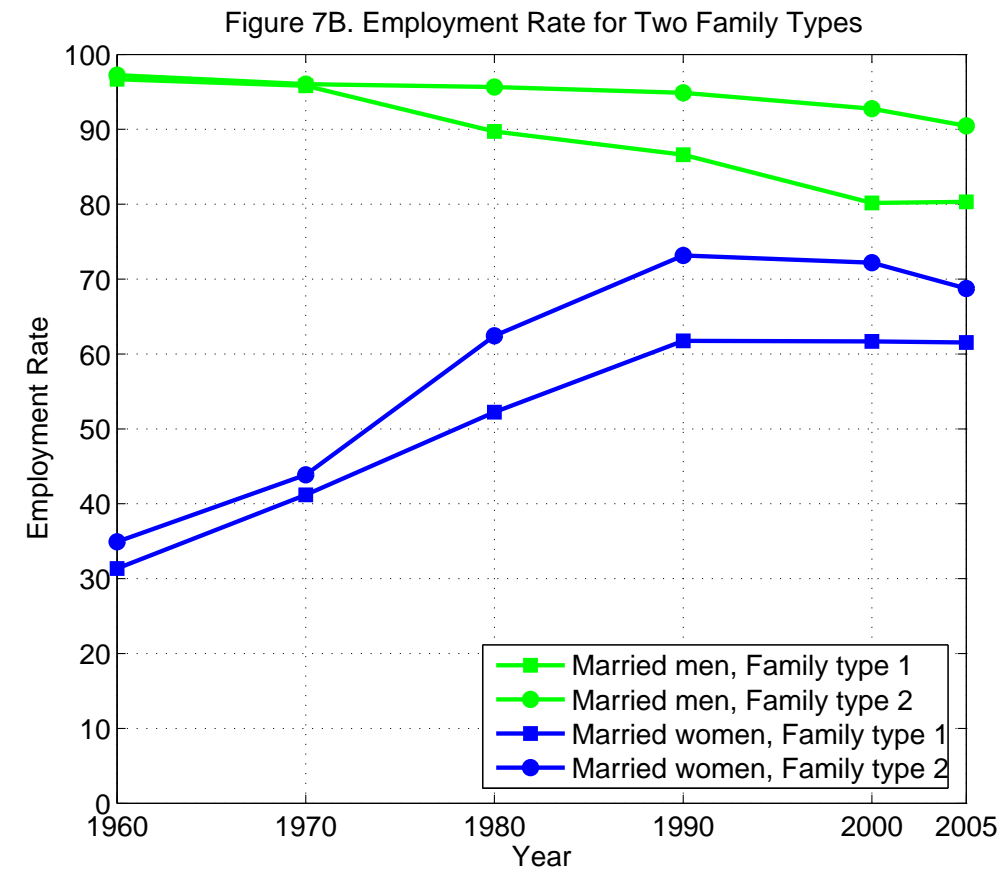

Figure 8A. Hours of Wives with no High School Degree,

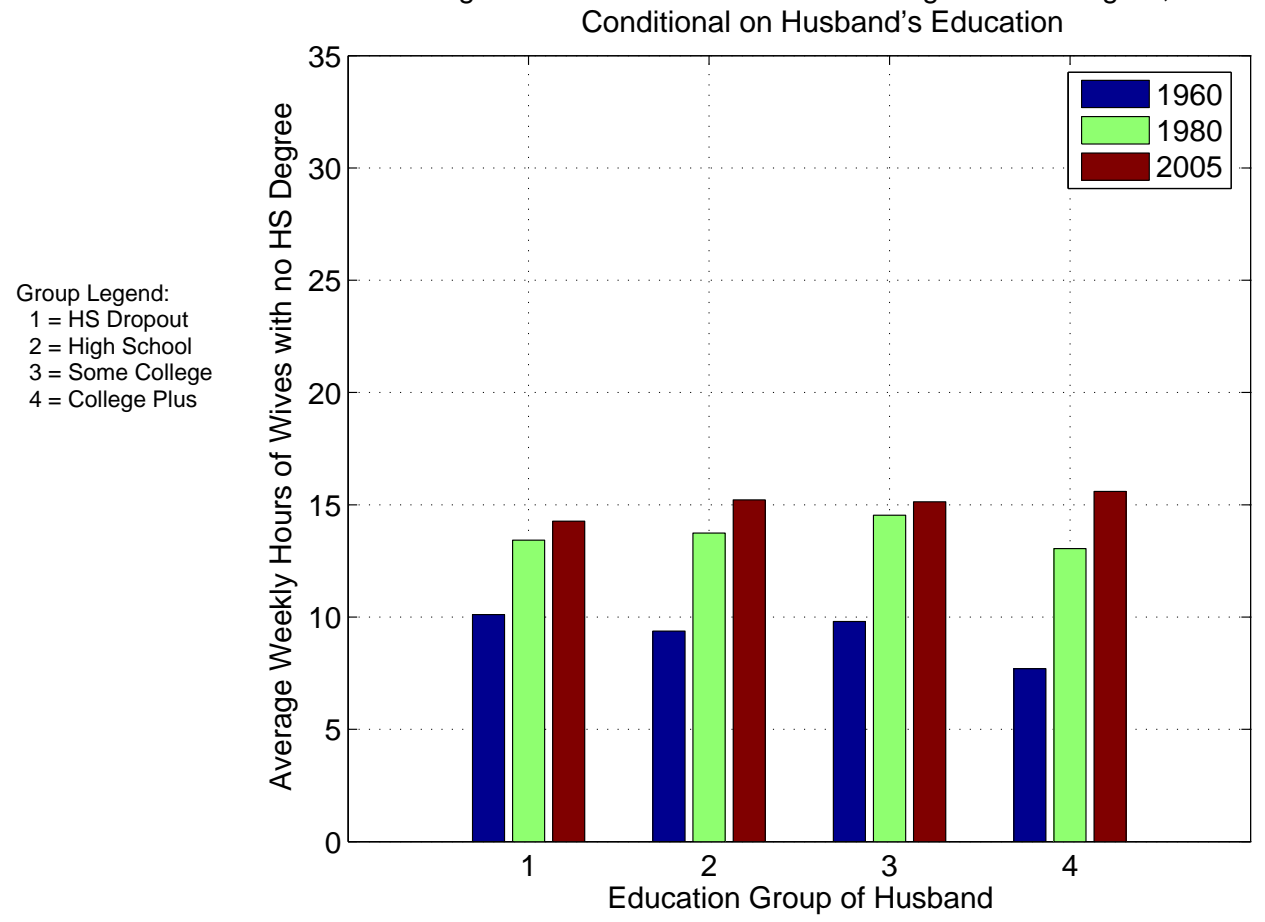




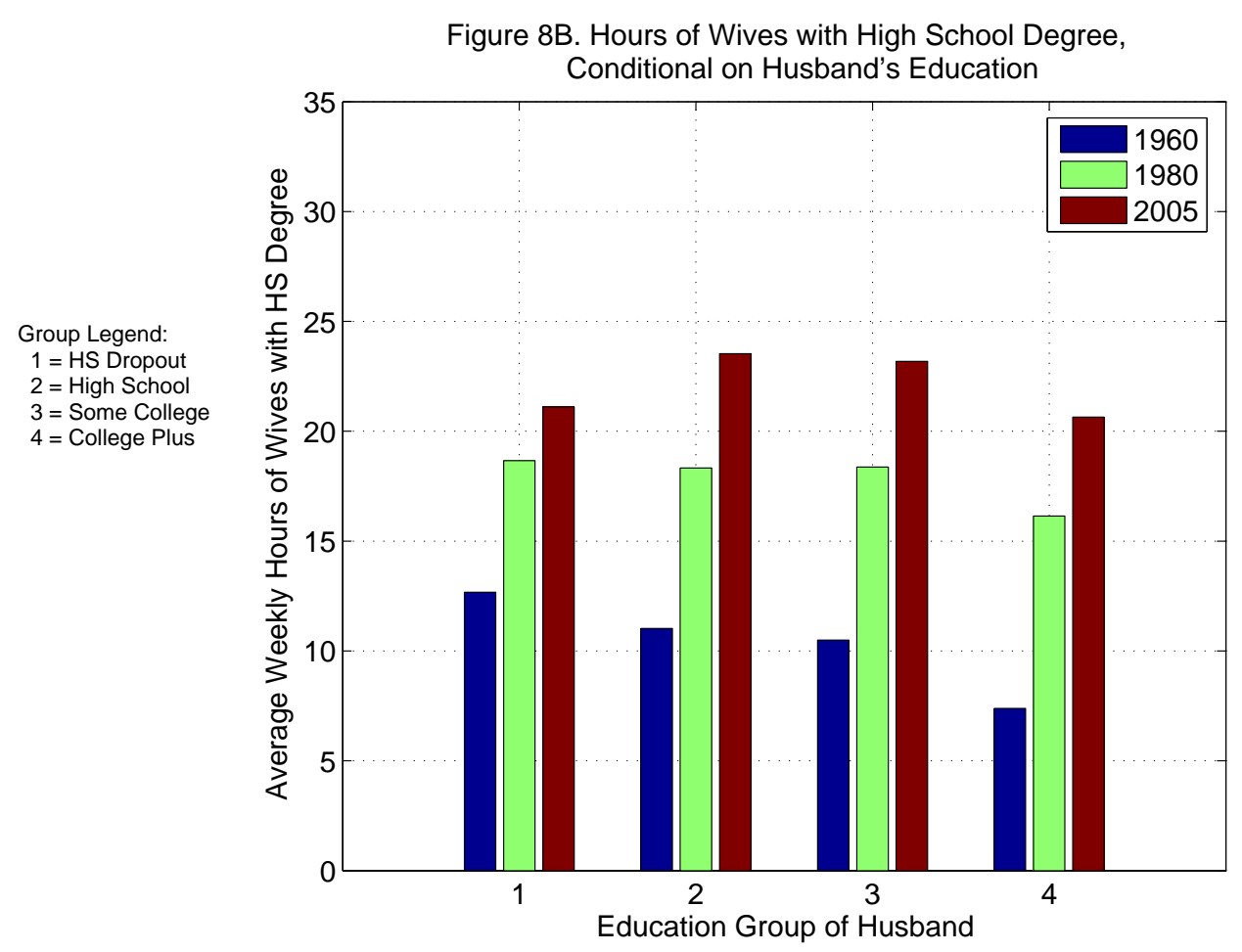

ings, women's hours have increased for all skill combinations. Second, in 1950 it is true not only that hours of work for women are independent of their skill level, but also that their hours of work are independent of the skill level of their spouses. This pattern changes over time, however. The tendency is for women's hours of work to be single peaked as a function of their husbands' skill level. In particular, as of 2005, except for the high school dropout group, holding the woman's educational attainment fixed, hours worked are lowest if the woman is married to a man from the highest educational attainment group.

\section{Time Use of Households}

The results shown in the final subsection of the preceding section tell us that as of 2005, there is substantial variation in total hours of market work across households in different skill groups. Since the seminal work of Becker (1965), the theory of the family has 
Figure 8C. Hours of Wives with Some College Education,

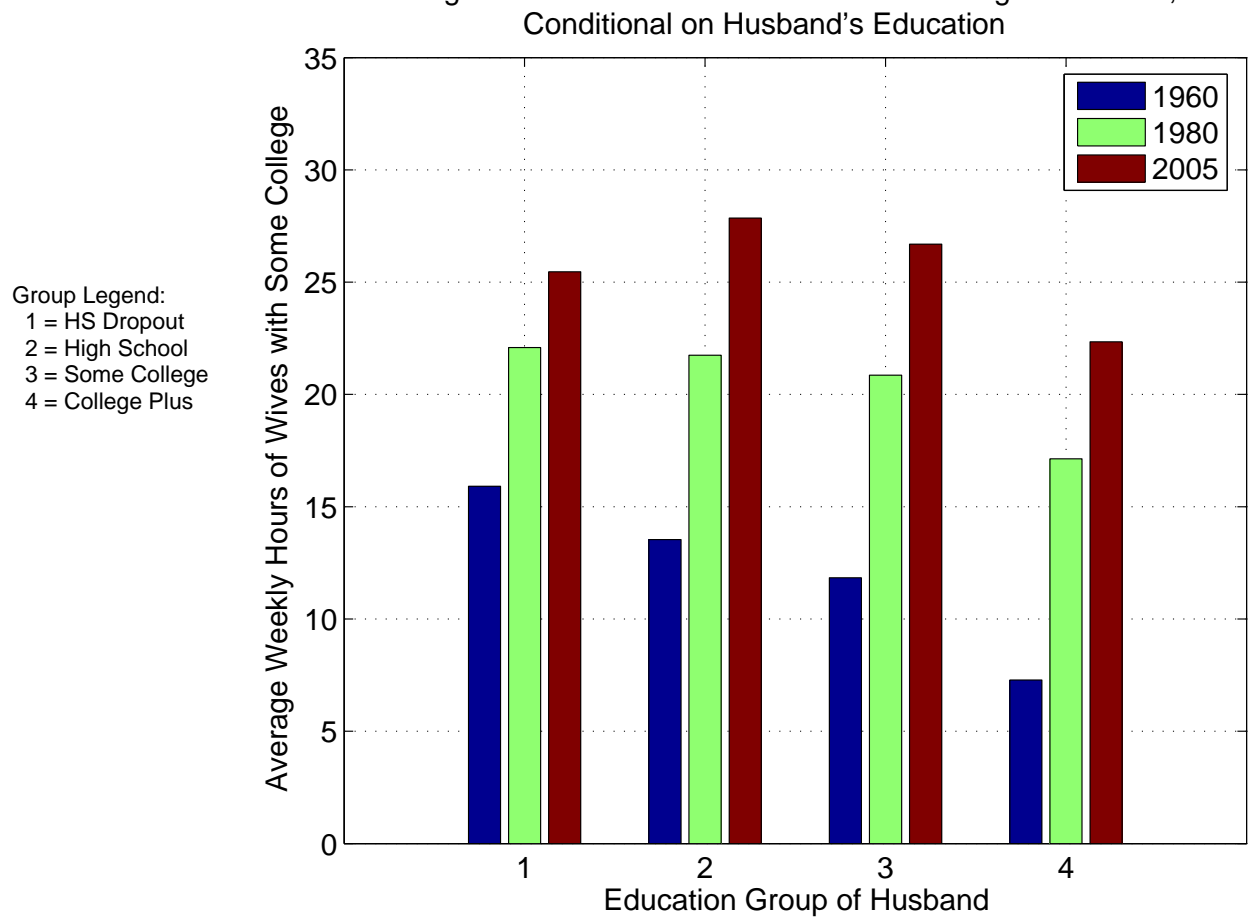

Figure 8D. Hours of Wives with College+ Education,

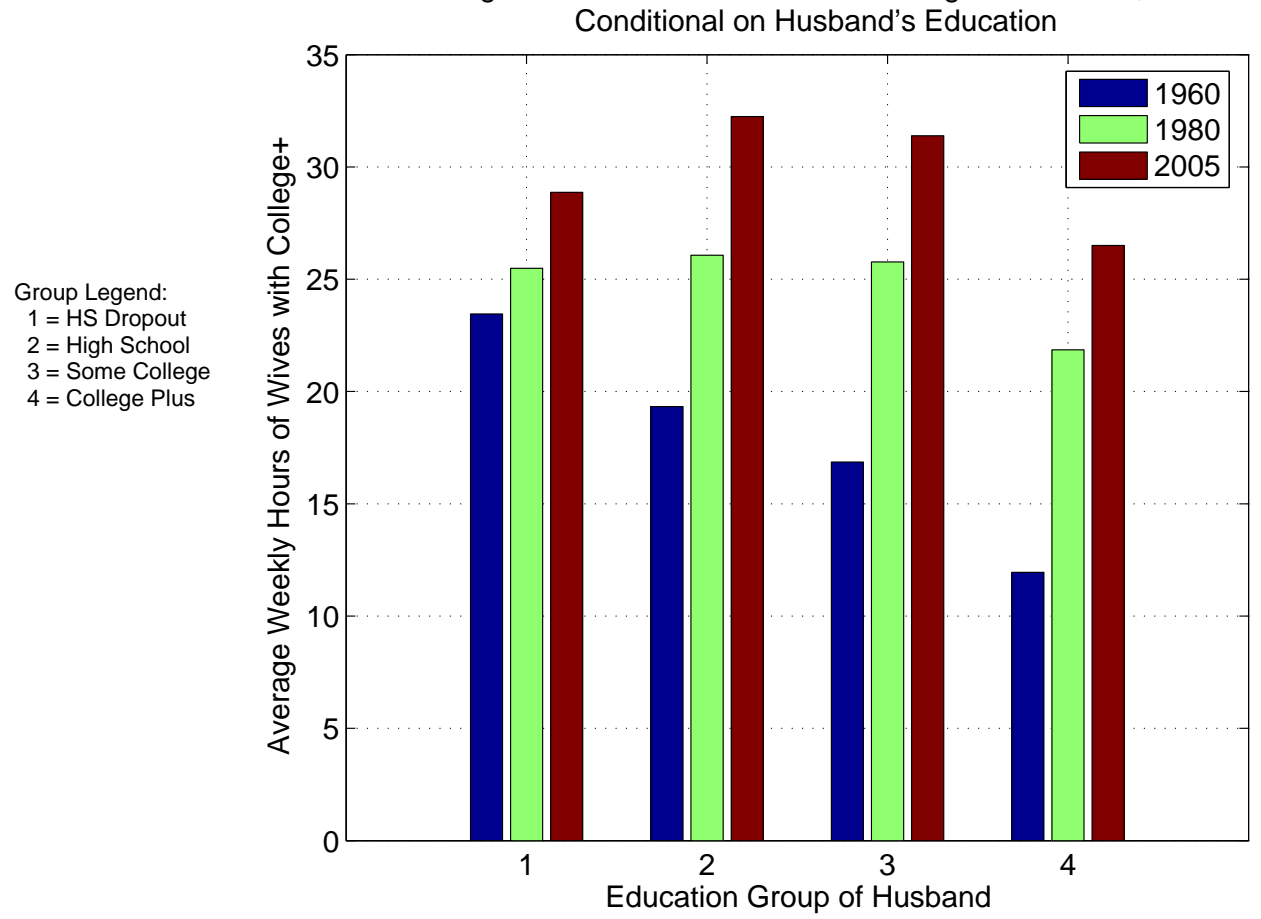


stressed that time devoted to market work is only one facet of the time allocation problem faced by a household. With this in mind, it is of interest to ask how differences in total hours of market work across households are related to other dimensions of time allocations. While one would like to be able to analyze these changes over time, sufficient data do not exist. While one would like to be able to analyze these changes over time, data limitations pose some problems. (See, however, Robinson and Godbey (1999), Aguiar and Hurst (2007), and Francis and Ramey (2007) for time series analysis of time allocations.) Here we use the recent American Time Use Survey (U.S. Department of Labor, BLS 2003-2004) to examine patterns in the recent cross-section. ${ }^{4}$

Table 1 displays time devoted to different activities for married females and married males differentiated by skill. We group activities into 10 categories: market work, housework, child care, shopping, personal care, education, organizations, socializing, sports and exercise, and leisure. We then aggregate activities further by combining housework, child care, and shopping for food into "home work" and all time that is not market work or home work into "other."

Given the results from the previous section, it is of particular interest to contrast the high school-educated couple with the college-educated couple. While one might have expected to see that less educated individuals spend less time in market production and more time in home production, Table 1 shows that this is not the case. To a large extent, the differences in market work are associated with equal but opposite differences in leisure. This result is in contrast to the theory of Ríos-Rull (1993), who explained the positive correlation of skill and hours of work in the cross-section of individuals as due to changes in the mix of 
market and home production in response to the differences in relative productivities. The pattern that we see in Table 1 would be consistent with a theory of heterogeneous agents and endogenous skill accumulation in which individuals who most value leisure choose to acquire less skill. A more detailed analysis of how leisure varies across individuals and how these changes have evolved over time is contained in Aguiar and Hurst (2007).

\section{Conclusion}

In this paper, we provide an overview of trends in family labor supply between 1950 and 2005. We compare single and married households and, for married households, we disaggregate by skill level.

Interesting patterns emerge from this exercise. Married women with the largest increase in market hours are those with high-skilled husbands, whether we measure skill by wage or education. This confirms earlier findings of Juhn and Murphy (1997), who condition on husband's wages only and work with a shorter sample. When we compare households with different skill mixes, we also find dramatic differences in the time paths, with higher skill households having the largest increase in average hours over time.

Given the importance of skill as a determinant of labor market opportunities and the large changes in the return to skill over time, we believe the summary of the data in this paper will be useful for researchers modeling the allocation of time within households. 


\section{Notes}

${ }^{1}$ For a broad review of the trends, see Costa (2000) and Goldin (1990). Recent examples of papers that build models to account for these trends include Attanasio et al. (2006), Greenwood et al. (2005), Jones et al. (2003), and Olivetti (2006).

${ }^{2}$ In McGrattan and Rogerson (1998, 2004), we left these individuals in our subsamples and adjusted aggregate figures to account for those that were not at work during the survey week.

${ }^{3}$ We present the picture for those aged 25-64 to be consistent with the evidence presented later in this paper. We note that the small increase in hours for those aged 25-64 has basically been offset with decreases for other age groups, so that as reported in McGrattan and Rogerson (2004), aggregate hours worked present virtually no trend over this period.

${ }^{4}$ Unfortunately, the BLS collects data from only one respondent per household. Therefore, we cannot investigate time allocations within households. 


\section{Appendix}

Here we provide the details on the construction of our measures of average hours and hourly earnings.

\section{A1. Samples}

We use Integrated Public Use Microdata Series (IPUMS) (U.S. Department of Commerce, Bureau of the Census 1950-2005) samples from the decennial census surveys and the American Community Survey. These are available at www.ipums.org. For all years, we have 1 percent samples. For 1970, we use the Form 1 state sample. For 1980 and 1990, we use the metro sample.

\section{A2. Variables}

The following variables were extracted from the IPUMS:

- SERIAL: household's serial number, 1950-2005

- PERNUM: person's assigned number in household, 1950-2005

- PERWT: person weight, 1950-2005

- AGE: age, 1950-2005

- SEX: sex, 1950-2005

- MARST: marital status, 1950-2005

- SPLOC: spouse locator, 1950-2005

- EMPSTATD: employment status, detailed, 1950-2005

- HRSWORK2: hours worked last week, 1950-1990

- UHRSWORK: usual hours worked per week last year, 1980-2005

- INCWAGE: wage and salary income, 1980-2005

- WKSWORK1: weeks worked last year, 1980-2005

- EDUCREC: educational attainment recode, 1960-2005 


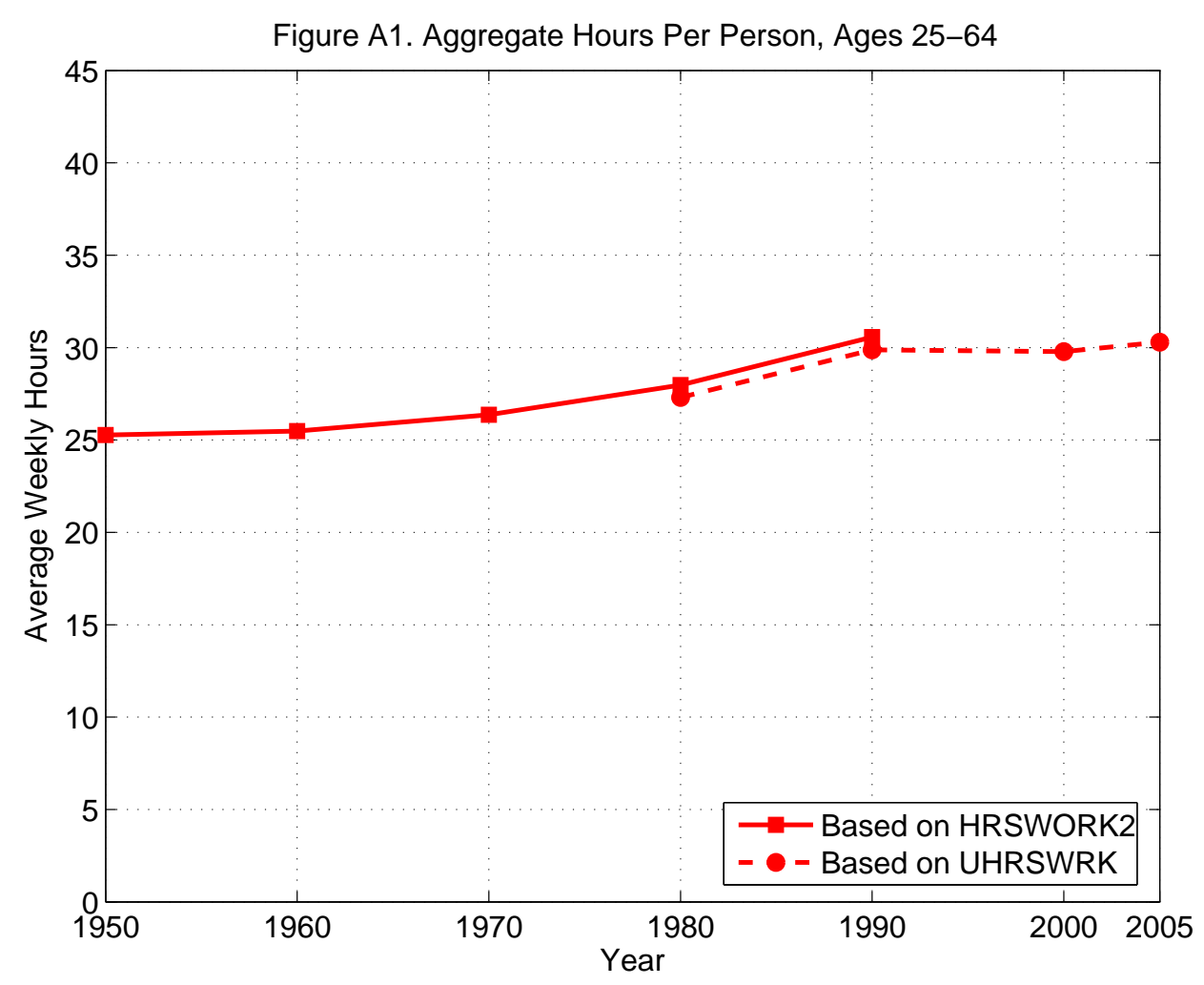

We use two measures of hours when constructing average hours. The first is HRSWORK2. The second is UHRSWORK for those who are employed and at work (EMPSTATD equal to 10, 11, or 14). In Figure A1, we show aggregate hours of work per person for individuals ages 25-64 using the two measures of hours. For 1980 and 1990, the HRSWORK2 series is about 0.7 hours per week higher than the UHRSWORK series. The change in hours, however, is roughly the same. To construct the data shown in Figure 1, we use the HRSWORK2 series in Figure A1 up to 1990 and then use estimates of the differences in UHRSWORK between 1990 and 2000 and between 2000 and 2005 to construct estimates for 2000 and $2005 .^{1}$

The INCWAGE variable has to be adjusted for inflation and for top-coded records. To adjust for inflation, we use the IPUMS adjustment factor based on the CPI for the reference year of reported wage and salary income. These are as follows: 2.29 in 1979, 1.34 in 1989, 1 in 1999, 0.85 in 2004. Top-coding adjustments are made by IPUMS for 1990 and later. We also use INCWAGE in 1980 and therefore must do our own adjustment. Here, we use the IPUMS top-code for 2000 to construct an adjustment factor for 1980 as follows. In 2000, any person with INCWAGE greater than $\$ 175,000$ had their actual wage replaced by the mean of all wages above $\$ 175,000$ in the state where he/she lives. Let $X$ be the set of all observations that are top-coded. Then the adjustment factor is

$$
f_{2000}=\frac{\sum_{i \in X} \operatorname{INCWAGE}(i) \operatorname{PERWT}(i)}{175000 \sum_{i \in X} \operatorname{PERWT}(i)}
$$


which is equal to 1.83 . We use this adjustment factor for 1980 to adjust top-coded wages.

After adjustments to INCWAGE are made, we construct hourly earnings as follows:

(A2) $\mathrm{HE}=\frac{\text { INCWAGE }}{\text { UHRSWORK } \times \text { WKSWORK1 }}$.

Because the incomes are reported for the year prior to the census survey year and the employment status is the status during the survey week, it is possible that some employed husbands have hourly earnings equal to 0 . We impute hourly earnings for those employed husbands that have a wage equal to $0 .^{2}$ The imputation is based on age and the educational attainment recode (EDUCREC). We constructed 16 groups, four age groups times four education groups. The four age groups are: 25-34, 35-44, 45-54, 55-64. The four education groups are: less than 12 years of schooling (EDUCREC=1:6), 12 years of schooling (EDUCREC $=7$ ), 13-15 years of schooling (EDUCREC=8), and 16 or more years of schooling $(\mathrm{EDUCREC}=9)$. Husbands with a wage of zero are assigned the average wage of the group to which they belong. 


\section{Appendix Notes}

${ }^{1}$ For a comparison of the two measures for other groups in the population, see the data and codes available at www.minneapolisfed.org.

${ }^{2}$ We also checked to see if our results changed when we dropped husbands having a wage of zero and found that they did not. 


\section{References}

Aguiar, Mark, and Eric Hurst. 2007. Measuring Trends in Leisure: The Allocation of Time Over Five Decades. Quarterly Journal of Economics, 122(3): 969-1006.

Attanasio, Orazio, Hamish Low, and Virginia Sanchez-Marcos. 2006. Explaining Changes in Female Labor Supply in a Life Cycle Model. Mimeo.

Becker, Gary S. 1965. A Theory of the Allocation of Time. Economic Journal, 75(299): $493-517$.

Costa, Dora L. 2000. From Mill Town to Board Room: The Rise of Women's Paid Labor. Journal of Economic Perspectives, 14(4): 101-122.

Francis, Neville, and Valerie Ramey. 2007. A Century of Work and Leisure. Mimeo.

Goldin, Claudia. 1990. Understanding the Gender Gap. Oxford University Press.

Greenwood, Jeremy, Ananth Seshadri, and Mehmet Yorukoglu. 2005. Engines of Liberation. Review of Economic Studies, 72(1): 109-33.

Jones, Larry, Rodolfo Manuelli, and Ellen R. McGrattan. 2003. Why are Married Women Working So Much? Staff Report 317, Federal Reserve Bank of Minneapolis.

Juhn, Chinhui, and Kevin M. Murphy. 1997. Wage Inequality and Family Labor Supply. Journal of Labor Economics, 15(1): 72-97.

McGrattan, Ellen R., and Richard Rogerson. 1998. Changes in Hours Worked Since 1950. Federal Reserve Bank of Minneapolis Quarterly Review, 22(1): 2-19.

McGrattan, Ellen R., and Richard Rogerson. 2004. Changes in Hours Worked, 1950-2000. Federal Reserve Bank of Minneapolis Quarterly Review, 28(1): 14-33.

Olivetti, Claudia. 2006. Changes in Women's Hours of Market Work: The Role of Returns to Experience, Review of Economic Dynamics 9: 557-87.

Ríos-Rull, José-Víctor. 1993. Working in the Market, Working at Home, and the Acquisition of Skills: A General-Equilibrium Approach. American Economic Review, 83(4): 893-901.

Robinson, John P., and Geoffrey Godbey. 1999. Time for Life: The Surprising Ways Americans Use Their Time. Second Edition. Pennsylvania State University Press.

U.S. Department of Commerce, Bureau of the Census. 1950-2005. Integrated Public Use Microdata Series. Available at http://www.ipums.org.

U.S. Department of Labor, Bureau of Labor Statistics. 2003-2004. American Time Use Survey series. Available at http://webuse.umd.edu. 
TABle 1. Time Use in hours of Married Persons Age 25-64

\begin{tabular}{|c|c|c|c|c|c|c|}
\hline \multirow[b]{2}{*}{ ACTIVITY } & \multicolumn{3}{|c|}{ Married Females } & \multicolumn{3}{|c|}{ MarRIED MALES } \\
\hline & Total & $\begin{array}{c}\text { Some } \\
\text { College } \\
\text { Education }\end{array}$ & $\begin{array}{l}\text { High } \\
\text { School } \\
\text { or Less }\end{array}$ & Total & $\begin{array}{c}\text { Some } \\
\text { College } \\
\text { Education }\end{array}$ & $\begin{array}{l}\text { High } \\
\text { School } \\
\text { or Less }\end{array}$ \\
\hline Market Work & 24.16 & 26.32 & 21.01 & 41.01 & 42.96 & 38.18 \\
\hline Housework & 18.98 & 17.57 & 21.05 & 10.46 & 10.32 & 10.67 \\
\hline Child care & 8.46 & 9.46 & 6.99 & 4.13 & 4.58 & 3.47 \\
\hline Shopping & 7.56 & 7.76 & 7.26 & 4.84 & 5.22 & 4.30 \\
\hline Personal care & 74.76 & 73.81 & 76.14 & 71.65 & 70.93 & 72.69 \\
\hline Education & 1.54 & 1.78 & 1.19 & 1.53 & 1.83 & 1.08 \\
\hline Organizations & 2.77 & 3.14 & 2.23 & 2.36 & 2.56 & 2.09 \\
\hline Socializing & 5.66 & 5.81 & 5.44 & 4.42 & 4.40 & 4.46 \\
\hline Sports/Exercise & 2.28 & 2.62 & 1.79 & 3.38 & 3.62 & 3.03 \\
\hline Leisure & 20.98 & 18.82 & 24.14 & 23.65 & 20.90 & 27.63 \\
\hline Not Available & 0.85 & 0.89 & 0.78 & 0.56 & 0.66 & 0.41 \\
\hline \multicolumn{7}{|l|}{ ADDENDUM: } \\
\hline Market Work & 24.16 & 26.32 & 21.01 & 41.01 & 42.96 & 38.18 \\
\hline Home Work ${ }^{\dagger}$ & 28.76 & 28.32 & 29.40 & 15.23 & 15.54 & 14.77 \\
\hline Other & 115.08 & 113.35 & 117.59 & 111.76 & 109.50 & 115.05 \\
\hline Total Hours & 168.00 & 168.00 & 168.00 & 168.00 & 168.00 & 168.00 \\
\hline
\end{tabular}

$\dagger$ Home work is the sum of housework, child care, and shopping for food.

Source: U.S. Department of Labor, BLS (2003-2004). 